SHORT REPORT

\title{
Peripheral opioids in inflammatory pain
}

\author{
G Watterson, R Howard, A Goldman
}

Arch Dis Child 2004;89:679-681. doi: 10.1136/adc.2003.032003

Topically applied opioids have provided effective analgesia without adverse effects, including tolerance, in adult patients with painful inflammatory conditions. The presumed mechanism of action is by interaction with opioid receptors which are sited on sensory nerve terminals and which may be upregulated in inflammation. The use of peripherally acting opioids has not been studied in paediatric patients. The use of topical morphine gel is reported in two children with epidermolysis bullosa, where acute inflammatory pain is a major symptom and where effective analgesia is a major clinical problem. The gel provided rapid reduction in pain scores in the patients and without any reported adverse effects or tolerance. A topical route of analgesia might be extremely beneficial for children with other painful skin lesions, including burns or post-surgical wounds, and further studies are now required.

E pidermolysis bullosa (EB) is a hereditary bullous disorder of the skin, in which minimal trauma causes chronic and severe blistering, which is extremely painful. Pain management in EB is a significant problem and is often unsatisfactory. ${ }^{1}$ A particular difficulty is the management of the acute pain associated with dressing changes. Our current practice is to use oral opioid analgesia for these and other procedures, which may take place on a daily basis. ${ }^{1}$ Unfortunately, opioid side effects and the development of tolerance are often troublesome, limiting the maximum dose that can be used.

Recently, peripheral analgesic effects of opioids have been shown in adults, and they have been used by local application for a number of painful conditions including arthritis and a variety of skin conditions. ${ }^{2}$ When used in this way, opioids, such as morphine, are thought to act through purely peripheral mechanisms. Significant plasma concentrations are not achieved, and therefore many of the side effects associated with this group of drugs such as tolerance and respiratory depression are avoided. ${ }^{3}$ Clearly this approach would have many advantages in young patients, but has not been reported to date. In this preliminary report we would like to discuss two cases of patients with EB in which topical morphine provided effective analgesia with apparently no opioid related adverse effects.

\section{CASE 1}

A 13 year old girl with a diagnosis of dystrophic epidermolysis bullosa had multiple denuded areas of skin as a result of recurring bullae formation. This form of EB is due to a disruption in the formation of the anchoring filaments that attach the basement membrane to the dermis. All types of dystrophic EB are due to a mutation in the gene for collagen type VII.

The patient required the use of regular analgesia and her current regimen was oral ibuprofen and slow release oral morphine ( $5 \mathrm{mg}$ twice daily) with short acting oral morphine sulphate solution ( $5 \mathrm{mg}$ once daily) for breakthrough and acute episodes of pain on an as required basis. Steady pain control was difficult to achieve and doses were constantly adjusted to try to balance analgesia and minimal side effects. She complained particularly that the sedative effects of oral opioids impaired her concentration and ability to learn at school, yet pain control was poor without them.

After discussion, and with the consent of the patient and her family, topical morphine was applied to the most painful areas of her skin at that time: neck, buttock, and groin. The morphine was made up in a gel formulation by combining morphine sulphate intravenous preparation (10 mg) with $15 \mathrm{~g}$ of Intrasite gel (a hydrogel preparation). The overall concentration of the mixture was $0.06 \%$, and the dose of morphine used was $0.2 \mathrm{mg} / \mathrm{kg}$. This gave an overall volume of $17 \mathrm{ml}$ of the gel mixture.

Analgesia was assessed by self report using a visual analogue scale ${ }^{4}$ before and one hour after gel application (fig 2).

There was an overall reduction in the pain scores of $55 \%$, $45 \%$, and $40 \%$ respectively for the neck, groin, and buttocks one hour after application of the morphine gel to these areas. The patient spontaneously reported that analgesia was maintained for some time after application and possibly lasted up to 24 hours.

To estimate the degree of systemic absorption, after four weeks of use, blood was taken for morphine and metabolite estimation before, and one hour after, a single application. At this time she was also taking 5-10 mg of slow release oral morphine and $5 \mathrm{mg}$ once daily of morphine sulphate solution. There was a slight increase in plasma morphine (table 1), but both pre- and post-topical morphine plasma morphine levels were substantially below the range of plasma levels associated with analgesia in the paediatric population. ${ }^{5}$ The patient also noted that she thought the skin on her buttocks had shown an improved degree of healing after four weeks of the morphine gel application. Five months later this patient is still using the morphine gel mixture and has reported no opioid side effects.

\section{CASE 2}

A 16 year old girl with dystrophic EB had an isolated, large skin lesion on her thigh, which was extremely painful and reduced her mobility. As before, $10 \mathrm{mg}$ of morphine sulphate was mixed in $15 \mathrm{~g}$ (again $0.2 \mathrm{mg} / \mathrm{kg}$ morphine used) of Intrasite gel and on this occasion applied on alternate days, at the time of dressing changes. She noted that there was an immediate cooling effect of the gel mixture after application and that it was less painful when she touched that area for a period of 24 hours after application. There was a reduction of $66 \%$ in the pain score one hour after the morphine gel application. This patient was opioid naïve and noted no adverse effects after using the morphine gel for a period of four weeks. Unfortunately the patient did not consent to blood drawing for morphine and morphine metabolite analysis. 


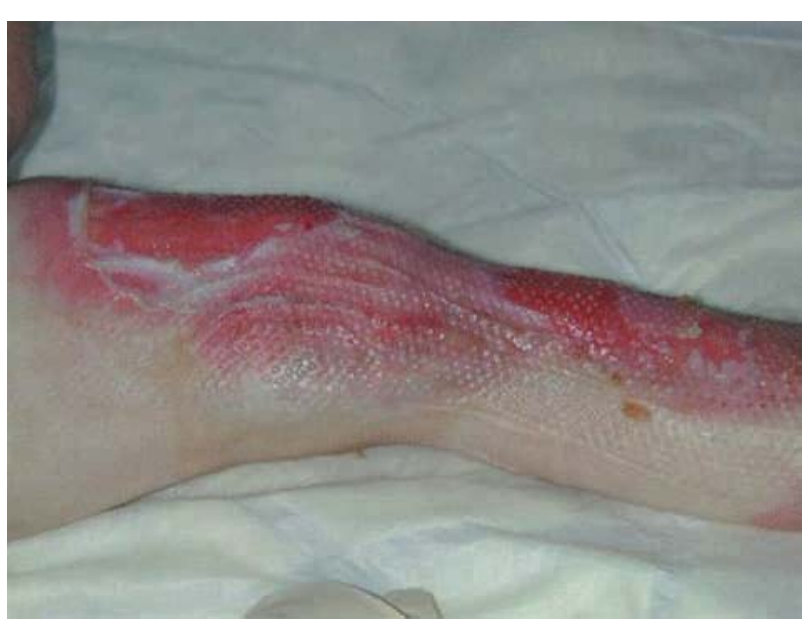

Figure 1 Typical skin lesion in dystrophic EB.

This patient also spontaneously commented that the area under the gel healed more quickly than usual.

\section{DISCUSSION}

The first use of peripheral opioid analgesia was intrarticular morphine, in the knee joint, of adult arthritis patients. Early clinical reports suggested that small doses (0.5-6 mg) provided analgesia lasting up to a maximum of 48 hours. ${ }^{6}$ These doses were lower than those required to provide adequate analgesia via a systemic route. Subsequent case studies in adults, using topical morphine or diamorphine mixed with Intrasite gel, in a variety of painful skin conditions such as diabetic ulcers, fungating malignancy, and sickle cell ulcers, have reported analgesic effects as early as 15 minutes after application and lasting up to a maximum of 45 hours. $^{78}$ An extremely low incidence of side effects and the absence of tolerance suggested there was no systemic absorption.

Intrasite gel is a water based gel, which has been used for pressure ulcers and other such painful skin lesions for some years. It has also been occasionally used for children with EB. Analgesia has not been reported when the gel has been used alone.

The mechanism of action of peripheral opioids is currently under investigation but may be due to interaction with peripherally located opioid receptors. ${ }^{9}$ Inflammation is

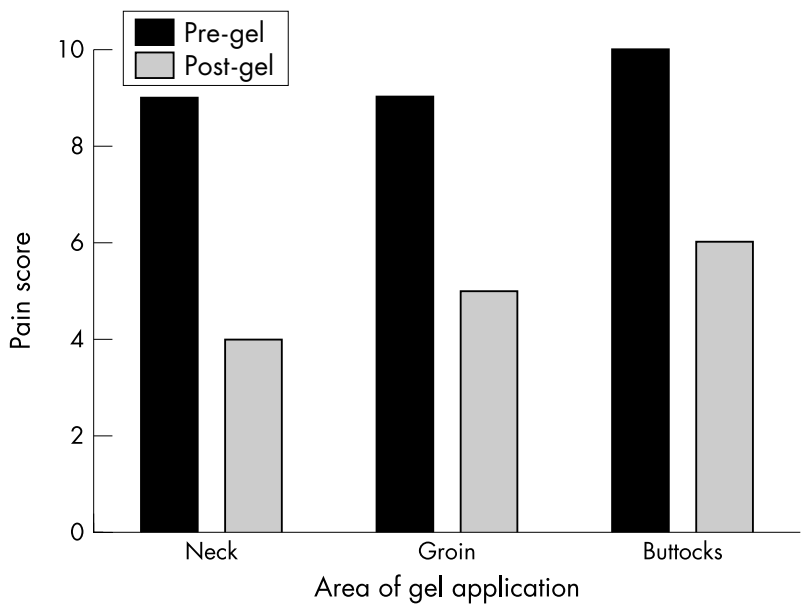

Figure 2 Pain scores pre- and one hour post-application of topical morphine.
Table 1 Morphine and its metabolites pre- and one hour post-topical morphine (case 1)

\begin{tabular}{lcccc}
\hline Metabolite & $\begin{array}{l}\text { Limit of } \\
\text { detection } \\
(\mathbf{n g} / \mathbf{m l})\end{array}$ & $\begin{array}{l}\text { Pre-gel level } \\
(\mathbf{n g} / \mathbf{m l})\end{array}$ & $\begin{array}{l}\text { 1 hour post-gel } \\
\text { level }(\mathbf{n g} / \mathbf{m l})\end{array}$ \\
\hline Morphine & 5 & $<5$ & 8 \\
Morphine-3-glucuronide & 60 & 156 & 174 \\
Morphine-6-glucuronide & 10 & 24 & 37 \\
\hline & & &
\end{tabular}

known to induce a number of changes in the skin including an increase in the number of peripheral sensory nerve terminals or "sprouting", disruption of the perineural membrane, as well as up-regulation of opioid receptor expression which are peripherally transported from the dorsal root ganglion (DRG) to sensory nerve terminals. ${ }^{10} 11$ It is interesting to note that although tolerance to peripheral opioids has previously been shown in animal models, ${ }^{12}$ tolerance did not appear to develop in adult humans using topical opioids for painful ulcers. ${ }^{6}$ The two cases discussed here also apparently did not experience tolerance to topical morphine, which is potentially a great advantage.

This is the first clinical report of the use of topical opioids in inflamed skin lesions in children. An encouraging analgesic response was observed in both cases, in keeping with previous observations in adults.

This novel and non-invasive approach offers the potential for good pain relief with reduced side effects. With the very low dose used here, $0.2 \mathrm{mg} / \mathrm{kg}$, it is unlikely that severe respiratory depression could occur, even if rapidly absorbed; however, very rapid absorption or the use of much higher doses may lead to undesirable effects. Potentially the technique could also be helpful in the management of other painful skin lesions, including burns, ulcerated vascular haemangiomas, or possibly even postoperative wounds. The incidental and unexpected reports of improved healing may also be important.

\section{Conclusion}

We report a long lasting peripheral opioid analgesia, with an additional healing effect, in two children with skin wounds due to EB. The apparently excellent efficacy and lack of adverse effects clearly warrants further systematic study.

\section{Authors' affiliations \\ G Watterson, Institute of Child Health, 30 Guilford Street, London WCIN 3EH, UK \\ R Howard, A Goldman, Great Ormond Street Hospital, London WCIN 3JH, UK}

Correspondence to: $\operatorname{Dr} G$ Watterson, Institute of Child Health, 30 Guilford Street, London WCIN 3EH; G.Watterson@ich.ucl.ac.uk

Accepted 22 November 2003

\section{REFERENCES}

1 Herod J, Denyer J, Goldman A, et al. EB in childhood-pathophysiology, anaesthesia and pain management. Paediatr Anaesth 2002;12:388-97.

2 Gupta A, Bodin L, Holmstrom B, et al. A systematic review of the peripheral analgesic effects of intra-articular morphine. Anesth Analg 2001;93:761-70.

3 Stein C, Pfluger M, Yassouridis A, et al. No tolerance to peripheral morphine analgesia in presence of opioid expression in inflamed synovia. J Clin Invest 1996;98:793-9.

4 McGrath P. Assessment of children's pain: a review of behavioural, physiological and direct scaling techniques. Pain 1987;31:147-76.

5 Collins J, Geake J, Houck HE, et al. Patient-controlled analgesia for mucositis pain in children. J Pediatr 1996;129:722-8.

6 Stein C. The control of pain in peripheral tissue by opioids. N Engl J Med 1995;332: 1685-90. 
7 Krajnik M, Zylicz Z, Finlay L, et al. Potential use of topical opioids in palliative care. Pain 1999;80:121-5.

8 Twillman RK, Long TD, Cathers TA, et al. Treatment of painful skin ulcers with topical opioids. J Pain Symptom Manage 1999;17:288-92.

9 Hassan H, Ableitner A, Stein C, et al. Inflammation of the rat paw enhances axonal transport of opioid receptors in the sciatic nerve and in creases their density in the inflamed tissue. Neuroscience 1993;55:185-95.
10 Antonijevic I, Mousa SA, Schafer M, et al. Perineural defect and peripheral opioid analgesia in inflammation. J Neurosci 1995; 15(1 pt 1):165-72.

11 Coggeshall RE, Zhou S, Carlton SM. Opioid receptors on peripheral sensory axons. Brain Res 1997:764:126-32.

12 Kolesnikov Y, Pasternak GW. Topical opioids in mice: analgesia and reversal of tolerance by a topical NMDA antagonist. J Pharmacol Exp Ther $1999 ; 290: 247-52$.

\section{Of people, pets, and pathogens, and dangerous shipments}

$\mathrm{T}$ his is a tale of cuteness and folly; it's about a furry animal, a potentially lethal virus, a man with two jobs, and a sinister intruder. The animal is the prairie dog; not a dog but a rodent, a short-tailed squirrel, that lives in burrows on the North American prairies; so cute that it is traded as a pet. The virus is the monkeypox virus, a member of the orthopoxvirus genus; it was first recognised as a cause of disease in captive primates in 1958 and the first cases of human monkeypox were reported from the Democratic Republic of Congo (then Zaire) in 1970. (The man and the sinister intruder? They will appear; I solicit your patience.)

Human monkeypox has occurred sporadically since 1970, but not outside Africa-until now. Between late May and late June 2003 (Kurt D Reed and colleagues. New England Journal of Medicine 2004;350:342-50; see also perspective article, ibid: 324-7) there were 72 confirmed or suspected cases in the USA. The first was a 3 year old girl in Wisconsin. Over the next 2 or 3 weeks there were 10 other cases in the state, all related to prairie dogs and a meat inspector. This meat inspector had a second job; he bought and sold exotic and unusual animals, including prairie dogs. Between mid-April and mid-May he bought 39 prairie dogs from a distributor in Illinois and in early May he took a sick giant Gambian rat recently arrived from Ghana (gentle and sensitive reader, I share your thoughts) from this distributor to a veterinary surgeon in Wisconsin. Many of the prairie dogs, though they were said never to have been in direct contact with the rat, subsequently became ill and not a few died. By the end of the first week in June eleven people in Wisconsin had developed confirmed (8) or suspected (3) monkeypox. They were: the meat inspector/animal dealer and his wife, the 3 year old girl and her parents who had bought two of the prairie dogs, two members of another household with two more of the prairie dogs, two people who worked in the two pet shops that sold the prairie dogs, and two vets who had each treated a sick prairie dog. Two patients had been bitten or scratched by a sick prairie dog and three had had minor open skin wounds from other causes when they were in contact with one of the animals. All eleven patients complained of headache and had monkeypox skin lesions (local nodular swellings around bites and scratches, a papular rash that became vesiculopustular, or both). Skin lesions at various stages of evolution were seen together and lesions might involve any part of the skin, the inside of the mouth, and the conjunctivae. The median time to crusting of all lesions was 12 days. Nine had fever, sweats, and chills and some had cough, lymphadenopathy, sore throat, and a variety of other signs and symptoms. All recovered. (Case fatality rates of up to $22 \%$ have been reported in Africa.) Monkeypox virus was isolated from seven patients and one prairie dog and its identity confirmed by detailed DNA studies. No information is given about the way in which it spread to infect another 61 people. There were no more cases after June 22.

Serological surveys in Africa have pointed to rodents and primates as carriers of monkeypox. A large shipment of six different species of African rodent arrived in the United States from Ghana on April 9, 2003. There are two types of monkeypox virus, West African and Congolese, and gene sequencing put the virus in this outbreak in the West African camp. Ghana is in West Africa.

The import of rodents from Africa into the USA has now been banned, as has the sale, distribution, transport, or release of prairie dogs or of six named African rodent species (Gambian giant pouched rats, brush-tailed porcupines, striped mice, tree squirrels, rope squirrels, and dormice). (How many other countries import these beasts? Could your children's new but already loved pet rabbit be at risk?)

Could the virus have infected American wildlife and could it become established in North America? Nobody knows. But the next time you trip over a brush-tailed porcupine by the shores of Lake Michigan, look out. And never introduce Floppy the bunny to a giant Gambian rat, pouched or not pouched. 